\title{
Famílias homoparentais e escola: reflexões e possibilidades
}

\author{
Mariana de Oliveira FARIAS ${ }^{1}$
}

\section{Introdução}

A sociedade brasileira atual é fortemente marcada pelas normas hegemônicas heterossexistas que ditam o ideal de família, de comportamentos relacionados ao gênero e orientação sexual.

O ideal de família ainda continua sendo a família nuclear, apesar de se constatarem outras diversas configuraçôes familiares igualmente favoráveis ao desenvolvimento do afeto e relaçóes entre os indivíduos, como as famílias monoparentais e homoparentais.

Para Petrini, Alcântara e Moreira (2009, p.260) a família tradicional tem se contrastado com os valores da formação de novas configuraçóes familiares:

A família participa dos dinamismos próprios das relaçôes sociais e sofre as influências do contexto político, econômico e cultural no qual está imersa. A perda de validade de valores e modelos da tradiçấo e a incerteza a respeito das novas propostas que se apresentam, desafiam-na a conviver com certa fluidez e abrem um leque de possibilidades que valorizam a criatividade numa dinâmica do tipo tentativa de acerto/erro. A família contemporânea

1 Faculdade Pitágoras. Cursos de Pedagogia e Psicologia. Jundiaí - SP - Brasil marianadeoliveirafarias@gmail.com 
caracteriza-se por uma grande variedade de formas que documentam a inadequação dos diversos modelos da tradição.

Uma destas formas de configuração familiar que tem ganhado grande visibilidade são as famílias formadas por pessoas de orientação sexual homossexual e seu(s) filho(s). No entanto, apesar da visibilidade, ainda é possível perceber preconceitos e carência na formação de profissionais que estão em contato direto com estas famílias, como é o caso daqueles que estão inseridos na área escolar.

\section{Objetivos}

Diante deste cenário, o objetivo deste trabalho foi refletir e analisar, a partir de publicaçóes na área de educação sexual, diversidade e homoparentalidade, de que forma mitos relacionados à homossexualidade e conceitos de família podem interferir na forma como a escola tem lidado com o tema da homoparentalidade.

\section{Método}

Foi realizada uma revisão da literatura sobre os temas: famílias homoparentais e escola, realizando uma análise crítica a respeito do papel da escola e dos profissionais da educação diante destas famílias.

\section{Revisão e análise da literatura: escola e famílias homoparentais}

As famílias possuem vínculo estreito com as instituições escolares que seus filhos frequentam, mantendo contato com professores, funcionários, coordenadores e mais esporadicamente, diretores. Mas de que forma as escolas tem recebido e lidado com as famílias homoparentais?

\section{Família, família: papai, mamãe, titia:} afinal qual o conceito de família?

O conceito de família modifica-se ao longo da história, contexto político e social em que estão inseridas. Podemos notar neste trecho do subtítulo, remetendo-se a uma música do Titãs, uma alusão à diversidade familiar, já na década de 90. Qual seria então o conceito de família? A música refere-se não somente à tradicional família nuclear, mas também à família extensa.

De acordo com Fonseca (2005, p.51), o conceito de família varia não somente em relação à sua configuração, mas também de acordo com a categoria social a que pertencem seus membros: 
[família] significa coisas diferentes dependendo da categoria social. Enquanto, entre pessoas da elite, prevalece a família como linhagem (pessoas orgulhosas de seu patrimônio), que mantêm entre elas um espírito corporativista, as camadas médias abraçam em espírito e em prática a família nuclear, identificada com a modernidade. Para os grupos populares o conceito de família está ancorada nas atividades domésticas do dia-a-dia e nas redes de ajuda mútua.

Para Uziel (2007), existe uma dificuldade contemporânea em definir o que seria família, mas esta continua sendo a instituição organizadora da sociedade contemporânea, tendo especial proteção do estado, de acordo com o artigo 226 da Constituiçãoo Federal Brasileira (BRASIL, 1888).

Juridicamente são consideradas famílias:

a) aquelas unidas pelo casamento entre homem e mulher (recentemente alguns estados do Brasil passaram também a reconhecer o casamento civil entre pessoas do mesmo sexo);

b) aquelas constituídas pelo pai ou mãe e seu(s) filho(a);

c) aquelas unidas pela união estável (recentemente o Supremo Tribunal Federal reconheceu as unióes estáveis também entre pessoas do mesmo sexo).

Apesar dos conceitos sobre família que constam na legislação e decisões do Supremo Tribunal Federal sobre as unióes entre pessoas do mesmo sexo, na visão de Fonseca (2005) é muito simplista ater-se ao conceito jurídico de família, muitas vezes apenas reafirmando os modelos hegemônicos.

Segundo Zanetti e Gomes (2009, p.195), referindo-se aos estudos de Roudinesco (2003) sobre a família da sociedade contemporânea, esta: "[...] une dois indivíduos em busca de relaçôes íntimas ou realização sexual [...]"

Diante da diversidade de configuraçóes familiares, a família homoparental emerge com grande visibilidade e reivindica direitos e serviços que a respeitem. Mas será que as escolas e os profissionais que nelas atuam estão preparados para lidar com a diversidade familiar e mais especificamente com a família homoparental?

\section{Mitos sobre a homossexualidade e a homoparentalidade}

Quando se fala de famílias homoparentais esbarramos na maioria das vezes com alguns questionamentos de pessoas que não reconhecem esta configuração familiar como válida. Os questionamentos geralmente estão relacionados ao conceito de família e aos mitos relacionados à homossexualidade. No quadro 1, podemos notar os principais mitos (crenças distorcidas) relacionados às famílias 
homoparentais e os esclarecimentos da literatura, de acordo com pesquisa realizada por Farias e Maia (2009), no qual levantaram os dados dos principais estudos na área.

Quadro 1 - Resumo dos Mitos sobre a Homoparentalidade e seus esclarecimentos a partir da análise da literatura consultada

\begin{tabular}{|c|c|}
\hline MITOS & $\begin{array}{c}\text { ESCLARECIMENTOS: DADOS DA } \\
\text { LITERATURA }\end{array}$ \\
\hline $\begin{array}{l}\text { 1) "Os homossexuais são } \\
\text { pessoas desajustadas ou sofrem } \\
\text { de distúrbios e por isso não } \\
\text { poderiam criar uma criança." }\end{array}$ & $\begin{array}{l}\text { Desde a década de } 1970 \text { a homossexualidade deixou } \\
\text { de ser considerada doença ou distúrbio, passando a ser } \\
\text { considerada um modo de ser. Além disso, outras pessoas } \\
\text { que não sáo homossexuais podem apresentar distúrbios } \\
\text { sem que eles tenham relação com a orientaçáo sexual. }\end{array}$ \\
\hline $\begin{array}{l}\text { 2) "Os homossexuais tendem } \\
\text { a abusar sexualmente das } \\
\text { crianças." }\end{array}$ & $\begin{array}{l}\text { Não há nenhum indício de que pessoas com orientação } \\
\text { sexual homossexual abusem mais de crianças que pessoas } \\
\text { com orientaçáo sexual heterossexual. }\end{array}$ \\
\hline $\begin{array}{l}\text { 3) "Se a criança for criada } \\
\text { por homossexuais, ela também } \\
\text { será homossexual." }\end{array}$ & $\begin{array}{l}\text { Não há relação direta entre a orientação sexual dos } \\
\text { pais, seja esta homossexual, bissexual ou heterossexual, } \\
\text { e a que os filhos terão na vida adulta. }\end{array}$ \\
\hline $\begin{array}{l}\text { 4) "A criança perderá a noção } \\
\text { de diferença entre os sexos por } \\
\text { ser criada por dois pais ou } \\
\text { duas mães." }\end{array}$ & $\begin{array}{l}\text { A criança poderá construir a noção de diferença entre } \\
\text { os sexos por meio de suas relaçôes sociais em geral; os } \\
\text { modelos de feminino e masculino não se restringem } \\
\text { apenas às figuras físicas de pai e de mãe. }\end{array}$ \\
\hline $\begin{array}{l}\text { 5) "É prejudicial para o } \\
\text { desenvolvimento da criança o } \\
\text { contato exclusivo com apenas } \\
\text { um tipo de papel sexual: } \\
\text { paterno ou materno." } \\
\end{array}$ & $\begin{array}{l}\text { Como já foi dito, os exemplos de papéis sexuais } \\
\text { extrapolam os modelos de pai e máe; além disso, os } \\
\text { papéis sexuais maternos ou paternos independem } \\
\text { de sexo biológico e podem ser assumidos tanto por } \\
\text { homens quanto por mulheres, na sociedade em geral. }\end{array}$ \\
\hline $\begin{array}{l}\text { 6) "As crianças vão } \\
\text { ter problemas em seu } \\
\text { desenvolvimento." }\end{array}$ & $\begin{array}{l}\text { Náo há diferenças significativas no desenvolvimento } \\
\text { físico e psicossocial entre filhos criados por pessoas gays } \\
\text { e lésbicas e filhos criados por pessoas heterossexuais. } \\
\text { Além disso, possíveis diferenças podem até ser } \\
\text { identificadas, mas não são atribuídas às características } \\
\text { da orientação sexual dos cuidadores e, sim, às } \\
\text { condiçôes diversas como: orgânicas, econômicas, } \\
\text { educacionais, sociais etc. }\end{array}$ \\
\hline $\begin{array}{l}\text { 7) "As crianças criadas por } \\
\text { casais homossexuais irão } \\
\text { sofrer mais por terem que } \\
\text { lidar sempre com a questäo do } \\
\text { preconceito social." }\end{array}$ & $\begin{array}{l}\text { O sofrimento diante da discriminação social em relação } \\
\text { a algum tipo de preconceito não se restringe à orien- } \\
\text { tação sexual, mas a diversos outros fatores igualmente } \\
\text { estigmatizantes, como raça, etnia, deficiências, pobreza } \\
\text { etc. }\end{array}$ \\
\hline
\end{tabular}

Fonte: Baseado em Farias e Maia (2009, p.87-88). 
Apesar dos esclarecimentos da literatura refutarem os mitos explicitados, ainda se nota que eles estão muito presentes na sociedade. Podemos afirmar então que eles se mantêm devido ao preconceito e dificuldade em lidar com a diversidade, já que não são sanados com dados científicos.

Antunes e Zuin (2008), explicam o preconceito, considerando a concepção de Adorno e Horkheimer, que afirmam que a ordem social hegemônica barbariza os homens a fim de sua manutenção.

A perseguição do outro, a repugnância compulsiva do inimigo imaginário, tem por essência a violência cotidiana que se faz manifesta contra tudo aquilo que náo conseguiu se ajustar totalmente, ou que acaba por ferir as "certezas" sobre as quais o progresso se sedimentou. (ANTUNES; ZUIN, 2008, p.38).

As famílias homoparentais ameaçam a ordem hegemônica heterossexista na qual a felicidade afetiva e sexual entre dois adultos e o bem estar de crianças e adolescentes somente podem ser alcançados na família formada pela uniáo entre um homem e uma mulher. Ao se constatar que as famílias homoparentais podem contribuir igualmente para estes fins, a sociedade se sente ameaçada, com medo de ter suas bases abaladas.

Percebe-se então que o preconceito presente em uma sociedade é exercido pelos indivíduos e instituiçóes que nela atuam. A escola torna-se assim um campo fértil de disseminaçáo ou elucidação do preconceito que precisa ser analisado.

\section{Uma análise da relação entre escola e famílias homoparentais}

A boa relação entre escola e família é fundamental para o bom desenvolvimento e adaptação social da criança ou do adolescente. Ademais, o reconhecimento e respeito da escola em relação à família de uma criança ou adolescente influencia diretamente no bem-estar psicológico deste aluno e também no comportamento de seus pares. No entanto, a escola parece, na maior parte das vezes, garantir a disseminação dos valores hegemônicos heterossexistas, como nos diz Lima (2011, p.13):

Nesse contexto de normatizaçáo quanto ao gênero e sexualidade, onde nos diversos âmbitos sociais, bem como na escola, os discursos hegemonicamente heterossexuais são disseminados, que a família homoparental procura se colocar de forma a garantir seu bem estar e inclusão social.

Mas então como as famílias homoparentais têm sido acolhidas nas escolas, se estas parecem não reconhecer aquelas? 
Em estudo realizado por Farias e Maia (2009), o relato de um dos participantes entrevistados que atuava na área da psicologia jurídica, confirma a dificuldade de alguns profissionais de educação em lidar com a temática:

(Tivemos que) intervir com isso junto à escola, chamar a diretora de escola, conversar, colocar, vamos dizer, às claras [...] o que estava acontecendo, e questionar posturas [...] É, na verdade a requerente, né, a guardiã acabou optando por tirar a criança da escola. [...] Porque ela viu que o osso era meio duro de roer, vamos dizer, não ia... ela ia só se machucar e machucar a criança [...] entrar num, num embate, tá?! Mas assim, serviu pra gente ir lá e posicionar essa diretora das posturas que ela tem que ter, ainda que não seja com essa criança mas com outras [...] e era algo assim [...] no caso a companheira na época ia buscar o menino. "Não, ela não é responsável pelo menino". Mas já que a própria guardiă delegou para ela, podia ser uma empregada dela, poderia ser o pai, poderia ser a irmã, poderia ser vizinha [...] É alguém que ela delegou responsabilidade [...] Então boicotava informaçôes para essa companheira dela [...] E alegavam que era porque não era responsável pela criança? [...] Você sabe que noventa por cento das pessoas que vão buscar a criança na escola não são responsável legal pela criança, são responsáveis delegados [...] (FARIAS; MAIA, 2009, p.182).

No entanto, também é possível perceber a abertura e respeito a estas famílias por uma parcela, ainda que menor, de outros profissionais da educação, como neste caso citado também pelo participante:

Náo teve problemas, teve uma aceitação supertranquila, sem [...] sem rótulos, vamos dizer assim. [...] Então... mas foram questóes assim que a gente foi trabalhar na escola, mas a solução encontrada, realmente foi tirar da [...] mudar de creche [...] tanto que na outra houve receptividade, né, então. (FARIAS, MAIA, 2009, p.183).

Em estudo realizado por Freitas e Dias (2012) com alunos do ensino médio (turma convencional e EJA) em escolas estaduais da cidade de Natal, foram apresentadas figuras com modelos de família nuclear, homoparental, monoparental masculina, monoparental feminina e um casal sem filhos. Apenas $27 \%$ dos alunos de ensino médio da turma tradicional e $28 \%$ dos alunos do ensino médio do EJA reconheceram a figura da família homoparental como configuração familiar.

Lima (2011) denuncia a invisibilidade das famílias homoparentais na sociedade, sendo responsáveis tanto os profissionais da escola, que na maioria não apresentam interesse em debater o tema, quanto às demais famílias que enxergam as famílias homoparentais com desprezo. 
Em seu estudo, a autora descreve o relato de uma professora que afirma que o tema da homossexualidade é delicado e difícil de ser trabalhado na escola. A professora afirma que muitos profissionais que atuam na escola não declaram abertamente, mas apresentam comportamentos preconceituosos em relação à homossexualidade e à capacidade dos casais homossexuais de criarem uma criança.

A questão que fica é: onde fica o papel da escola como instituição da educação, que deveria preparar os indivíduos para atuarem de forma cidadá na sociedade? A escola também contribui para o fortalecimento do preconceito e dos mitos que envolvem as famílias homoparentais:

Também a falta de esclarecimento da própria instituição fomenta que esses preconceitos impeçam a problematizaçáo a respeito da homoparentalidade e possibilitem que antigos paradigmas permaneçam sendo uma barreira entre a escola e as famílias compostas por casais homossexuais. (LIMA, 2011, p.26).

Cadete, Ferreira e Silva (2012) também relatam o afastamento da escola em discutir temas sobre a diversidade familiar. As autoras realizaram um estudo de caso em uma escola pública na cidade de Recife-PE, no qual entrevistaram diferentes representantes da escola: cinco professores do Ensino Fundamental, cinco alunos, um coordenador, diretor e vice-diretor, uma merendeira, um porteiro e um profissional dos serviços gerais. As autoras identificaram que, de forma geral, a família homoparental não é reconhecida como família e não é refletida ou discutida no âmbito escolar.

$\mathrm{Na}$ visão das autoras, a invisibilidade da família homoparental provoca vergonha por parte dos membros das famílias homoparentais que preferem permanecer no silêncio. No entanto, este silêncio e invisibilidade é muito prejudicial para a criança:

Esse silêncio (em relação às famílias homoparentais) pode ser interpretado como o reflexo da ilegalidade e do preconceito, que permeiam a composiçáo familiar homoafetiva, em que a maior vítima é a criança. Logo, o não reconhecimento dessa união como família provoca um sentimento de vergonha para os sujeitos da relação homoparental que, por sua vez, preferem silenciar quanto a sua identidade familiar. Essa legalidade é imprescindível para que a criança adquira confiança em si mesma e nos outros. (CADETE; FERREIRA; SILVA, 2012, p.110).

A escola parece estar alheia ao tema das famílias homoparentais e nega sua existência, apesar de tolerá-la na invisibilidade. Desta forma descarta os estudos na área que demonstram que crianças que convivem com famílias homoparentais apresentam adaptaçấo social e psíquica adequadas, mas que podem sofrer 
preconceito devido à homofobia e neste sentido a escola teria papel fundamental de enfrentamento e esclarecimentos sobre os mitos envolvidos.

\section{Conclusões}

Diante dos dados e análises apresentadas, conclui-se que as concepçôes sobre o conceito de família e em relação à homossexualidade ainda influenciam fortemente o comportamento e aceitação social diante das famílias homoparentais. A falta de esclarecimentos e reflexão sobre o tema é perpetuado na escola pelo não reconhecimento, invisibilidade e silêncio em relação aos membros destas famílias. Há clara homofobia da grande parte dos profissionais que atuam nas escolas, ainda que esta homofobia ocorra pela invisibilidade,

Esta postura negligente de grande parte dos profissionais da educaçáo e a falta de incentivo do Governo em apoiar ações que visem minimizar o preconceito em relação à diversidade sexual e familiar prejudica muito a adaptação social saudável dos membros destas famílias e, principalmente as crianças, que estão em plena fase de desenvolvimento e construção da sua identidade.

Acredita-se ser fundamental que sejam realizados programa de formação continuada para profissionais da educação que discutam o tema da diversidade familiar e que os instrumentalize da lidar com seus membros na prática escolar.

Parece também ser de grande importância o desenvolvimento de materiais didáticos e paradidáticos que trabalhem o conceito de família, suas diversas configuraçóes e o respeito à diversidade sexual.

A escola como instituição que visa preparar o indivíduo para a cidadania não pode se abster do seu papel e deve rever suas práticas visando a atuaçáo de forma respeitosa e responsável diante da sociedade contemporânea.

\section{REFERÊNCIAS}

ANTUNES, D. C.; ZUIN, A. A S. Do bullying ao preconceito: os desafios da barbárie à educação. Psicologia e Sociedade, Porto Alegre, v.20, n.1, p.32-42, abr. 2008. Disponível em: <http://www.scielo.br/pdf/psoc/v20n1/a04v20n1.pdf>. Acesso em: 19 nov. 2015.

BRASIL. Constituiçáo da República Federativa do Brasil. Brasília, 1888. Disponível em: $<$ http://www.planalto.gov.br/ccivil_03/Constituicao/Constituicao.htm>. Acesso em: 19 nov. 2015.

CADETE, V. G.; FERREIRA, S. P. A.; SILVA, D. B. Os sentidos e os significados produzidos pela escola em relação à família homoparental: um estudo de caso. Interaçáo em Psicologia. [Paraná], v.16, n.1, p.101-112, 2012. Disponível em: <http://ojs.c3sl.ufpr.br/ojs2/index. php/psicologia/article/view/13947/19720 >. Acesso em: 19 nov. 2015.

FARIAS, M. O.; MAIA, A. C. Adoçáo por homossexuais: família homoparental sob o olhar da psicologia jurídica. Curitiba: Juruá, 2009. 
FONSECA, C. Concepçôes de família e práticas de intervenção: uma contribuição antropológica. Saúde e Sociedade, São Paulo, v.14, n.2, p.50-59, maio/ago. 2005. Disponível em: <http://www.scielo.br/pdf/sausoc/v14n2/06.pdf>. Acesso em: 19 nov. 2015.

FREITAS, L. R. M.; DIAS, R. L. Discutindo valores da escola: homoparentalidade e novos conceitos de família. Quipus, v.1, n.2, p.101-107, jun./nov. 2012. Disponível em: <http:// portal.unp.br/arquivos/pdf/institucional/edunp/quipus_a1n2.pdf>. Acesso em: 19 nov. 2015.

LIMA, S. S. Escola e família: problematizaçóes a partir da homoparentalidade. 2011 Trabalho de conclusão de curso (Monografia) - UFRS, Porto Alegre, 2011.

PETRINI, J. C.; ALCÂNTARA, M. A. R.; MOREIRA, L. V. C. Família na contemporaneidade: uma análise conceitual. In: MENEZES, J. E. X.; CASTRO, M. G. (Org.). Família, populaçáo, sexo e poder: entre saberes e polêmicas. São Paulo: Paulinas, 2009. p. 257-274.

UZIEL, A. P. Homossexualidade e adoçáo. Rio de Janeiro: Garamond, 2007.

ZANETTI, S. A. S.; GOMES, I. C. A ausência do princípio de autoridade na família contemporânea brasileira. Psico, v.40, n.2, p.194-201, 2009. Disponível em: <http:// revistaseletronicas.pucrs.br/ojs/index.php/revistapsico/article/view/3799/4533>.Acesso em: 19 nov. 2015 


\section{Resumo}

\section{Familias homoparentais e escola: reflexóes e possibilidades}

As normas hegemônicas heterossexistas presentes na sociedade privilegiam relaçóes e comportamentos que as ratifiquem e consequentemente, crenças e valores que as fortaleçam. Desta forma, as configuraçóes familiares que não condizem com o modelo heterossexual, como a família homoparental, são desfavorecidas nas relaçóes sociais, legislação e políticas públicas. Diante deste cenário, o objetivo deste trabalho é refletir, a partir de publicaçóes na área de educação sexual, diversidade e homoparentalidade, de que forma mitos relacionados à homossexualidade e conceitos de família podem interferir na forma como a escola lida com a homoparentalidade. Algumas crenças distorcidas influenciam a visão social sobre a homoparentalidade como: a) pessoas de orientação sexual homossexual seriam promíscuas e náo proporcionariam um ambiente adequado ao desenvolvimento sadio de uma criança; b) pessoas de orientação sexual homossexual sofreriam de algum tipo de desvio ou distúrbio e por isso não deveriam cuidar de uma criança; c) crianças que convivem com pais/mães homossexuais sofreriam muito preconceito o que prejudicaria seu desenvolvimento e adaptaçáo social, obrigatoriamente; d) a criança perderia a noção de diferença entre os gêneros e isso afetaria seu desenvolvimento e convívio social; e) a criança tenderia a ser homossexual também; f) a criança interpretaria a relação homossexual como adequada, o que poderia prejudicar seu desenvolvimento e convívio social. A escola, como instituição inserida na sociedade, e os profissionais que nela atuam, encontram-se submersos nestas crenças distorcidas, tendo também suas práticas influenciadas. Estudos mostram que grande parte dos profissionais da área da educação não conta com formação inicial ou continuada que aborde de forma crítica e reflexiva temas sobre sexualidade ou diversidade familiar. A falta de materiais didáticos que apresentem a diversidade familiar existente na sociedade também dificulta o trabalho da escola com as famílias. Conclui-se fazer-se necessário e urgente investir na formação de professores e na elaboração de materiais didáticos sobre diversidade familiar, educação sexual e diversidade sexual para que os profissionais de educaçáo e consequentemente a escola, estejam preparados para acolher e interagir de forma adequada e respeitosa com as diversas configuraçóes familiares, incluindo a família homoparental. A escola, ao contribuir para o acolhimento da diversidade familiar e sexual existente na sociedade, estará contribuindo também para uma formação mais crítica dos seus alunos e combatendo a homofobia.

PALAVRAS-CHAVE: Famílias homoparentais. Escola. Formação de professores

\section{Abstract}

\section{Homoparental families and school: reflections and possibilities}

The heterosexist hegemonic rules present in the society privilege relations and behavior that ratify them and consequently the beliefs and values that build them up. In this way, the familiar settings which don't match with the heterosexual model as a homoparental family are disadvantaged into the social relations, legislation and public policy. According to this, the aim of this paper is to reflect from the publications in the area of sex education, diversity and homoparenthood, in which way the myth related to homosexuality and family concepts can interfere on the way that the school deals with homoparenthood. Some distorted beliefs influence the social view about homoparenthood like: a) Some people of sex orientation homosexual would be promiscuous and wouldn't provide a good environment to a healthy development for a child; b) Some people of sex orientation homosexual would suffer some 
kind of disturbance e because of this couldn't take care of a child; c) Children who live with homosexual father/mother would suffer a lot of prejudice which would damage their development and social adaptation; d) The child would lose the notion of the difference between the genders and it would affect its development and social intimacy; $f$ ) The child would tend to be homosexual too; g) The child would interpret the homosexual relation as adequate, what could prejudice its development and social living. The school, as an institution in the society, and the professionals who act in them are inserted into these distorted beliefs and these may influence their practice. Some studies show that most of the professional in education doesn't have initial training or continuing that approach in a critical and reflexive subjects about sexuality or familiar diversity. The lack of teaching material that shows the familiar diversity presented in the society also interferes in the school work. Then it's strongly necessary to invest in the teaching training and in the formulation of teaching material as well. Acting in this way the school and its professionals will be prepare to welcome and interact, in a good way, with all families configurations and will contribute for a better critical formation of its students and will help to combat the homophobia.

Keywords: Homoparental families. School. Teacher training. 
